\title{
Acrolein and Copper as Competitive Effectors of $\alpha$-Synuclein
}

\author{
Enrico Falcone, ${ }^{[b, c]}$ Ikhlas M.M. Ahmed, ${ }^{[a, b]}$ Valentina Oliveri, ${ }^{*[b]}$ Francesco Bellia, ${ }^{*[a]}$ Bertrand \\ Vileno, ${ }^{[\mathrm{c}, \mathrm{d}]}$ Youssef El Khoury, ${ }^{[\mathrm{e}]}$ Petra Hellwig, ${ }^{[\mathrm{e}, \mathrm{f}]}$ Peter Faller ${ }^{*[\mathrm{c}]}$ and Graziella Vecchio. ${ }^{[\mathrm{b}]}$ \\ [a] Istituto di Cristallografia, Consiglio Nazionale delle Ricerche, via P. Gaifami 18, 95126 Catania, Italy \\ ${ }^{[b]}$ Dipartimento di Scienze Chimiche, Università degli Studi di Catania, viale A. Doria 6, 95126 Catania, Italy \\ [c] Institut de Chimie, UMR 7177, CNRS, Université de Strasbourg, 4 Rue Blaise Pascal 67000, Strasbourg, France \\ [d] French EPR Federation of Research, Fédération IR-RPE CNRS, 67081 Strasbourg, France \\ ${ }^{\text {[e] } L a b o r a t o i r e ~ d e ~ b i o e ́ l e c t r o c h i m i e ~ e t ~ s p e c t r o s c o p i e, ~ U M R ~ 7140, ~ C N R S, ~ U n i v e r s i t e ́ ~ d e ~ S t r a s b o u r g, ~} 4$ Rue Blaise Pascal, F-67081, \\ Strasbourg, France

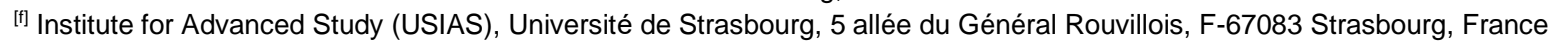

\begin{abstract}
Mounting evidence supports the role of amyloidogenesis, oxidative stress, and metal dyshomeostasis in the development of neurodegenerative disorders. Parkinson's Disease is characterized by a-Synuclein (aSyn) accumulation and aggregation in brain regions, also promoted by $\mathrm{Cu}^{2+}$. aSyn is modified by reactive carbonyl species, including acrolein (ACR). Notwithstanding these findings, the interplay between ACR, copper, and aSyn has never been investigated. Therefore, we explored more thoroughly the effects of ACR on aSyn using an approach based on LC-MS/MS analysis. We also evaluated the influence of $\mathrm{Cu}^{2+}$ on the protein carbonylation and how the ACR modification impacts the $\mathrm{Cu}^{2+}$ binding and the production of Reactive Oxygen Species (ROS). Finally, we investigated the effects of $\mathrm{ACR}$ and $\mathrm{Cu}^{2+}$ ions on the aSyn aggregation by dynamic light scattering and fluorescence assays. $\mathrm{Cu}^{2+}$ regio-selectively inhibits the modification of His50 by ACR, the carbonylation lowers the affinity of His50 for $\mathrm{Cu}^{2+}$ and ACR inhibits aSyn aggregation both in the presence and in the absence of $\mathrm{Cu}^{2+}$.
\end{abstract}

\section{Introduction}

Parkinson's disease (PD) and a group of diseases collectively referred to as the $\alpha$-synucleinopathies are characterized by the progressive loss of neuronal cells and the decline of cognitive and motor functions. Biochemical and neuropathological evidence supports the role of $\alpha$-synuclein ( $\alpha \mathrm{Syn}$ ), oxidative stress, and metal dyshomeostasis in the development of these disorders. ${ }^{[1-3]}$ aSyn is a presynaptic protein and in its monomeric form is an intrinsically disordered protein with no persistent secondary structure. Although it remains unclear how aSyn initiates neuronal death, mounting evidence suggests that the aggregation of aSyn to form oligomers and fibrils is a crucial event in the pathogenesis of $\alpha$-synucleinopathies. ${ }^{[4,5]}$

Metal-protein interactions play an important role in aSyn aggregation and might represent a link between the pathological processes of protein aggregation, oxidative damage, and neural death. In PD, there is also a disconnected set of data that implicate copper dyshomeostasis. Copper is elevated in the cerebrospinal fluid of PD patients and is associated with Lewy bodies, the intracellular aggregates of aSyn. ${ }^{[6]}$ Copper regulates aSyn intracellular localization and cytotoxicity, and aSyn-copper interaction influences the production of Reactive Oxygen Species (ROS). ${ }^{[7,8]}$ aSyn and $\mathrm{Cu}^{2+}$ form different complex species (Figure 1A):[9] at low pH $(<6)$ the first equivalent of $\mathrm{Cu}^{2+}$ binds to the $\mathrm{N}$-terminal amino acids Met1 and Asp2 in a $2 \mathrm{~N}_{2} \mathrm{O}\left(\mathrm{NH}_{2}, \mathrm{~N}^{-}, \mathrm{COO}\right.$, Owater) «species 1», $[10,11]$ while at pH 7.4 His50 replaces water forming a $3 \mathrm{~N} 1 \mathrm{O}\left(\mathrm{NH}_{2}, \mathrm{~N}-\mathrm{Nim}, \mathrm{COO}-\right)$ «species $1^{\prime \prime » ; ; 12]}$ a second $\mathrm{Cu}^{2+}$ ion binds more weakly[13] to His50 in a 2N2O/3N1O ( $\left.\mathrm{Nim}, \mathrm{N}-\mathrm{N}-\mathrm{O}, \mathrm{O}\right)$ "species 2», while the first equivalent occupies species 1.[14] Finally, $\mathrm{Cu}^{2+}$ also binds to a non-specific «site 3 » at the C-terminal region (loop Asp119-Met127).[15]

Lipoxidation and carbonylation have also been observed in neurodegenerative diseases. ${ }^{16,17]} \alpha$ Syn seems to induce lipid peroxidation, ${ }^{[18]}$ and, conversely, $\alpha$ Syn carbonylation has been found in PD. ${ }^{[19]}$ Lipoxidation leads to the formation of the so-called Reactive Carbonyl Species (RCS), namely $\alpha, \beta$-unsaturated carbonyls, such as acrolein (ACR, 2-propenal) and 4-hydroxy-nonenal (HNE), and dicarbonyl compounds. In particular, ACR and HNE have been reported to affect the aggregation process of aSyn. ${ }^{[20-25]}$ The adducts between aSyn and HNE have been extensively characterized by in vitro experiments, and His50 resulted in being the main modification site. ${ }^{[26,27]}$ Notwithstanding these findings, the adducts ACR- $\alpha$ Syn have been less explored and characterized. Moreover, the interplay between ACR, copper, and aSyn has never been investigated even if a mutual influence between copper-binding and carbonylation may exist since His50 is involved in both $\mathrm{Cu}^{2+}$ binding and the modification by $\alpha, \beta$-unsaturated aldehydes.

Therefore, we explored more thoroughly the dose- and time-dependent effects of ACR on aSyn using an approach based on Ultra Performance Liquid Chromatography (UPLC) coupled with High-Resolution Mass spectrometry (HRMS). Moreover, we evaluated the effects of $\mathrm{Cu}^{2+}$ ions on these chemical modifications, and the influence of His carbonylation on $\mathrm{Cu}^{2+-b i n d i n g}$ and the following catalytic activity in ROS production drawing upon native and His-modified model peptides of aSyn $\mathrm{Cu}^{2+-b i n d i n g ~ s p e c i e s . ~ F i n a l l y, ~ w e ~ i n v e s t i g a t e d ~ t h e ~ e f f e c t s ~}$ of ACR and $\mathrm{Cu}^{2+}$ ions on $\alpha$ Syn aggregation by ThT fluorescence assay and dynamic light scattering (DLS). 


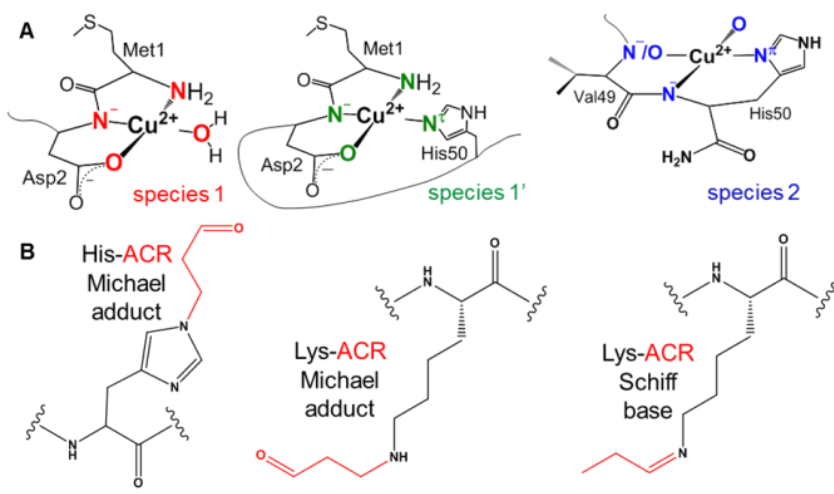

Figure 1. A) Schematic structure of the specific $\mathrm{Cu}^{2+}$-binding sites of aSyn. B) Structure of ACR adducts with His and Lys residues.

\section{Results and Discussion}

ACR forms covalent adducts with aSyn

It is well-known that ACR and other lipoxidation products lead to covalent protein modifications targeting the nucleophilic side chains of cysteine, ${ }^{[28]} \mathrm{His},{ }^{[29]}$ and Lys residues. ${ }^{[30]}$ In particular, aSyn does not contain any cysteine residue but includes only one His residue (His50) and as many as fifteen Lys residues.

To explore the molecular mechanisms of interaction between ACR and aSyn, we performed a series of experiments using an approach based on a UPLC- HRMS system.

The reactivity between aSyn and ACR was initially evaluated by performing a kinetic measurement of the covalent adducts formed upon the reaction between ACR and aSyn (Figure 1B). Spectra deconvolution analysis allows identifying the formation of Michael and Schiff base adducts between aSyn and ACR (Figure $1 \mathrm{~B}$ and Table S1).

When the [aSyn]:[ACR] molar ratio is 1:10, the $1: 1$ adduct ( $\mathrm{SSyn}+\mathrm{ACR}$ ) was observed after $1.5 \mathrm{~h}$, but also the $1: 2$ adduct ( $\alpha$ Syn+2ACR) was appreciably formed (Figure S1). Their content, as well as the formation of other carbonylated aSyn species, increased over time. However, the signals resulting from unmodified aSyn did not disappear, and unmodified aSyn was the main species at $21 \mathrm{~h}$ (Figure S1).

A dose-dependent effect of ACR on the reaction with aSyn was also observed (Figure S2). The data show that after $6 \mathrm{~h}$, significant modification occurred from ratios greater than 1:1. Many high-molecular-weight adducts were observed at $\alpha$ Syn:ACR 1:50 ratio. Therefore, the extent of $\alpha$ Syn modification also depends on $\alpha$ Syn:ACR molar ratio.

Based on these data and in order to characterize the early stages of the carbonylation of aSyn, we chose to set the aSyn:ACR molar ratio and the maximum reaction time as 1:10 and $90 \mathrm{~min}$, respectively. After the carbonylation process, the reaction samples were treated with $\mathrm{NaBH}_{4}$ to quench the excess of $\mathrm{ACR}$ and stabilize the aSyn-ACR adducts, thus preventing further secondary and cross-linking reactions. The trypsin digestion yielded several peptides, analyzed by UPLC-HRMS. The high accuracy of the detected $\mathrm{m} / \mathrm{z}$ values related to the most abundant peptides ions, coupled to their MS/MS acquisition allowed to identify the peptide sequence (Table S2). All the detected ACR-linked peptides derived from the formation of Michael adducts between ACR and the side chain amino groups of Lys and His, whereas covalently linked ACR-peptides based on Schiff base conjugates were not detected.

Figure 2 reports the formation of the main aSyn tryptic peptides that do not contain any missed-cleavage, as a function of the incubation time with ACR. The non-carbonylated peptides have similar intensity, except for the smaller tryptic peptide aSyn $1-6$, suggesting that they have similar ionization properties. Moreover, their formation was not significantly affected by the ACR reaction, thus confirming the low percentage of aSyn modification. aSyn $46-58$ carbonylated at the His residue is the only tryptic peptide without missed-cleavages whose formation significantly increases in a time-dependent manner. The chromatogram of the ACR-modified aSyn46-58 shows two distinguished peaks (Table S2, RT 14.73 and $14.92 \mathrm{~min})$, related to isobaric peptides $(\mathrm{m} / \mathrm{z}$ 677.3724). The fragmentation pattern depicted by the MS/MS spectra of both the isomers (Figure S3) confirms that, in both cases, the His residue is covalently linked to ACR. Two different $\mathrm{N}^{\mathrm{T}}$ - and $\mathrm{N}^{\top}$-substituted regioisomers could be hypothesized as previously observed in the case of HNE and N-acetyl-His. ${ }^{[31]}$ 


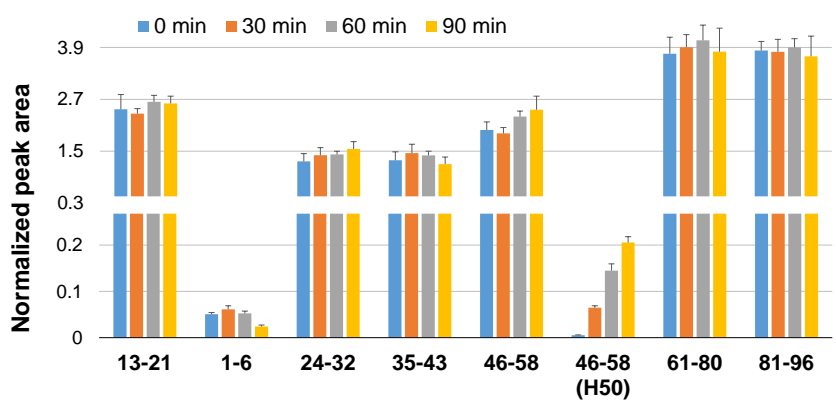

Figure 2. Formation of the main aSyn tryptic peptides that do not contain any missed-cleavage. Bars related to each peptide are reported as a function of the incubation time with ACR. The carbonylated residue (H50) is shown in parentheses.

The involvement of His on the aSyn-ACR reaction is therefore confirmed, but the reactivity of the Lys residues cannot be analyzed from these data (Figure 2). Indeed, the trypsin-mediated digestion close to the basic residues of aSyn (Lys residues) is inhibited if the side-chain of the Lys group is covalently linked to ACR. Therefore, the analysis of tryptic peptides containing missed-cleavages is necessary to examine the formation of ACR modifications on the Lys residues. In the presence of ACR, only two tryptic peptides containing missedcleavages ( $\alpha S_{5 y} n_{59-80}$ and $\alpha S_{41} n_{81-97}$ ) were not modified by ACR (Figure S4). However, their intensity was much lower than that formed without missed-cleavages (Figure 2), and their amount rapidly decreased during the ACR-aSyn reaction.

On the contrary, the formation of the ACR-linked tryptic peptides containing missed-cleavages (Figure S4, right side bar graph) was promoted by the reaction with the aldehyde. Ten out of the fifteen Lys residues are involved by the ACR modification, although an evident scale of reactivity cannot be drawn from the data. It is worth pointing out that the ACR-modified tryptic peptides aSyn $44-58$ and aSyn $46-60$ have the same molecular weight and encompass His residue. The MS/MS characterization of these peptides (Figures S5 and S6) allowed to assign the correct sequence to each LC signal and also revealed that the carbonylated site was the internal Lys residue ( $\mathrm{K} 45$ and $\mathrm{K} 58$ ).

\section{$\mathrm{Cu}^{2+}$ binding reduces the extent of His50 modification}

The effect of copper ions on aSyn modification by ACR was evaluated, monitoring the extent of tryptic peptides modification over reaction time by exploring several $\mathrm{Cu}^{2+}: \alpha \mathrm{Syn}$ molar ratios. The staked area graph reported in Figure 3A compares the modification percentage of the main ACR-modified tryptic peptides after 90 min reaction (containing or not missed cleavages) as a function of the $\mathrm{Cu}^{2+}$ : $\alpha$ Syn molar ratio. Without copper ions $\left(\mathrm{Cu}^{2+}: \alpha \mathrm{Syn} 0: 1\right)$, it is clear that the $\alpha \mathrm{Syn}_{46-58}$ modified at the His residue shows the higher fraction percentage of ACR-linked peptides (Table S3). Such a result highlights that the higher reactivity of His towards the ACR modification, compared to that of the Lys residues, greatly counterbalances the disfavoured His:Lys number ratio (1:15). As the $\mathrm{Cu}^{2+}$ concentration increases, the ACR-modified aSyn $46-58$ is significantly reduced. All the other carbonylated peptides at the Lys residue are affected to a much lower extent comparing to the modification at His50. Such a regioselective effect of $\mathrm{Cu}^{2+}$ towards the ACR reaction can also be observed after 30 or 60 minutes (Figure S7).

This different effect can be explained by the different involvement of Lys residues and His50 in the $\mathrm{Cu}^{2+}$ binding. In particular, His50 binds to the $\mathrm{Cu}^{2+}$ in $\mathrm{Cu}^{2+}$ - $\alpha$ Syn (1:1) at $\mathrm{pH} 7.4$ (species 1'), but it is not involved in the $\mathrm{Cu}^{2+}$ binding at lower $\mathrm{pH}$ values ( $\mathrm{pH} 6$, species 1$)$. In order to assess that the $\mathrm{Cu}^{2+}$ coordination by His50 accounts for the inhibition of the ACR carbonylation on the same residue, the influence of the $\mathrm{pH}$ was also evaluated (Figure 3B). Experiments were hence performed at $\mathrm{pH} 6$, where imidazole protonation hinders $\mathrm{Cu}^{2+-}$-binding to His50. Under acidic condition and without the addition of copper ions ( $\mathrm{Cu}^{2+}: a S y n ~ 0: 1$ molar ratio), the extent of the carbonylation is significantly lower than that detected at physiological $\mathrm{pH}$, because of the protonation state of His side-chain; furthermore, the dose-dependent inhibition effect of $\mathrm{Cu}^{2+}$ reported at $\mathrm{pH} 7.4$ is almost totally abolished at $\mathrm{pH}$ 6.0. The determining role of $\mathrm{pH}$ confirms that $\mathrm{Cu}^{2+}$ modulates the His reactivity towards ACR only when it is in species $1^{\prime}\left(\mathrm{Cu}^{2+}: \mathrm{aSyn} 1: 1, \mathrm{pH} 7.4\right)$ or species $2\left(\mathrm{Cu}^{2+}: \mathrm{aSyn} 2: 1, \mathrm{pH} 7.4\right)$, whereas it does not if $\mathrm{Cu}^{2+}$ is bound to species $1(\mathrm{pH} 6)$. Overall, the ACR reaction with His depends on the $\mathrm{pH}$ and the $\mathrm{Cu}^{2+}:$ aSyn ratio.

\section{Characterization of a His-modified aSyn model peptide}

To evaluate whether the modification of His influences the $\mathrm{Cu}^{2+}$-binding, we resorted to short peptides that are considered suitable models of aSyn $\mathrm{Cu}^{2+-b i n d i n g ~ s i t e s .[10,14] ~ H e n c e, ~ w e ~ s y n t h e s i z e d ~ t w o ~ m i n i m a l ~ m o d e l ~}$ peptides, aSyn $1-5\left(\mathrm{NH}_{2}-\mathrm{MDVFM}-\mathrm{NH}_{2}\right)$, and Ac-aSyn46-50 (Ac-EGVVH-NH 2$)$, hereafter called $\mathrm{P} 1$ and $\mathrm{P} 2$, respectively, so that species 1 is modeled by Cu-P1, species 2 by Cu-P2 and species 1 ' by the ternary complex Cu-P1-P2. Cu-P1 (species 1), Cu-P2 (species 2), and Cu-P1-P2 (species 1') show CD and EPR signatures analogous to those reported in the literature (Figure S8), ${ }^{[14]}$ making them suitable models of $\alpha$ Syn $\mathrm{Cu}^{2+-b i n d i n g}$ 
sites. Then, a carbonylated form of the model peptide P2, P2ACR, was synthesized. ESI-MS analysis of the resulting $\mathrm{P} 2 \mathrm{ACR}$ showed five protonated species (Table S4), the mono- ([P2+ACR]), and bis-modified $([\mathrm{P} 2+2 \mathrm{ACR}])$ adducts, and their hydrated forms ([P2+ACR+ $\left.\left.\mathrm{H}_{2} \mathrm{O}\right],\left[\mathrm{P} 2+2 \mathrm{ACR}+\mathrm{H}_{2} \mathrm{O}\right],\left[\mathrm{P} 2+2 \mathrm{ACR}+2 \mathrm{H}_{2} \mathrm{O}\right]\right)$. However, the mono-adducts, both hydrated or not, are the main product of P2 modification. Among all the MS/MS peptide fragments of the species $\left[\mathrm{P} 2+\mathrm{ACR}+\mathrm{H}_{2} \mathrm{O}\right] \cdot \mathrm{H}^{+}($Table S5), only those containing the His-ACR adducts were detected as hydrated forms. NMR analysis (Figure S9A) also shows the hydrated mono-modified species as the primary component (signal at $4.95 \mathrm{ppm}$ can be attributed to the methine hydrogen of the geminal diol group, $-\mathrm{CH}(\mathrm{OH})_{2}$ ), together with a lower percentage of mono-carbonylated peptide (aldehyde proton signal at $9.58 \mathrm{ppm}$ ). The modification of P2 by ACR is also confirmed by the downfield shift of His protons signals compared to P2. Besides, NOESY spectrum shows the correlation of the protons of the methylene group attached to His nitrogen (4.20 ppm) with both His protons (7.31 and $8.60 \mathrm{ppm})$, suggesting that the propanal group is attached to the His $\mathrm{N}^{\tau}$ nitrogen (Figure S9B).

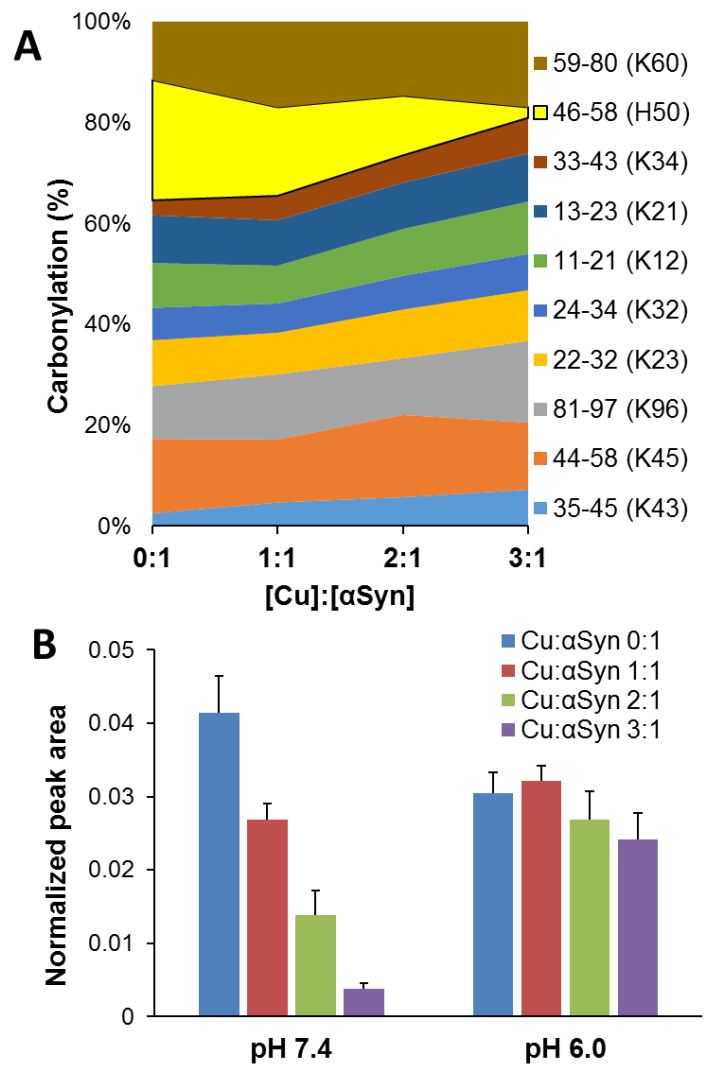

Figure 3. A) Modification percentage of the main ACR-linked tryptic peptides after 90 min reaction, as a function of the Cu²+: $a$ Syn molar ratio. The carbonylated residues are shown in parentheses. B) Effect of the $\mathrm{pH}$ on the copper-dependent formation of the tryptic peptide aSyn (46-58) modified by ACR at the $\mathrm{H} 50$ residue.

His modification affects species 1' formation

The impact of His derivatization on copper binding was then evaluated through spectroscopic techniques. In particular, we compared the spectral features of the complexes $\mathrm{Cu}-\mathrm{P} 2^{\mathrm{ACR}}$ and $\mathrm{Cu}-\mathrm{P} 1-\mathrm{P} 2^{\mathrm{ACR}}$ to those of the native complexes. Cu-P2 and $\mathrm{Cu}-\mathrm{P} 2^{\mathrm{ACR}}$ show very similar $\mathrm{CD}$, EPR, and FTIR spectra (Figures 4A, 4B, and 4C), leading to conclude that His modification by ACR does not affect the formation of species 2. Indeed, FTIR spectra given in Figure $\mathrm{S} 10$ show upon $\mathrm{Cu}^{2+-}$ binding to P2/P2ACR the appearance of a band at $1185 / 1188 \mathrm{~cm}^{-}$ ${ }_{1}\left(\mathrm{~N}^{\mathrm{T}}-\mathrm{C} 2\right.$ stretching), which is an indicator of His binding to $\mathrm{Cu}^{2+}$ via $\mathrm{N}^{\pi} .{ }^{[32]}$ Thus, $\mathrm{Cu}^{2+}$ binds to $\mathrm{N}^{\pi}$ in the complex $\mathrm{Cu}-\mathrm{P} 2^{\mathrm{ACR}}$ as in the native complex Cu-P2 (Figures 1 and $\mathrm{S} 11$ ).

On the contrary, the EPR spectrum of Cu-P1-P2ACR appears to be slightly shifted downfield with respect to that of Cu-P1-P2 (Figure 4D): in particular, it shows g// values intermediate between those of Cu-P1 and Cu-P1-P2 (Figure 4 and Table S6), suggesting that P2ACR His binds only partially. Indeed, this spectrum is well-fitted by a linear combination of Cu-P1 and Cu-P1-P2 spectra in a 1:1 ratio (Figure S12A and Table S6). Moreover, the addition of a 2.4-fold excess of P2ACR gave rise to a spectrum (Figure 4D) closer to that of Cu-P1-P2 complex (Table S6), which fits conveniently with the linear combination of Cu-P1 and Cu-P1-P2 spectra in about 1:3 ratio (Figure S12B and Table S6). Hence, the modified His of $\mathrm{P} 2{ }^{\mathrm{ACR}}$ shows affinity in binding to $\mathrm{Cu}-\mathrm{P} 1$ lower 
affinity than $\mathrm{P} 2$ in binding to $\mathrm{Cu}-\mathrm{P} 1$. Based on previous studies, ${ }^{[33,34]}$ we speculate that $\mathrm{His}$ binds $\mathrm{Cu}^{2+}$ via the more exposed $\mathrm{N}^{\tau}$ in the ternary complex Cu-P1-P2, whereas $\mathrm{N}^{\tau}$-modified His binds $\mathrm{Cu}^{2+}$ through $\mathrm{N}^{\pi}$ in the $\mathrm{Cu}$ P1-P2ACR complex. The higher steric hindrance of the modified His could account for the lower affinity observed. In summary, His $\mathrm{N}^{\tau}$ modification by ACR seems not to influence species 2, but it may reduce the affinity of His in species 1 '.
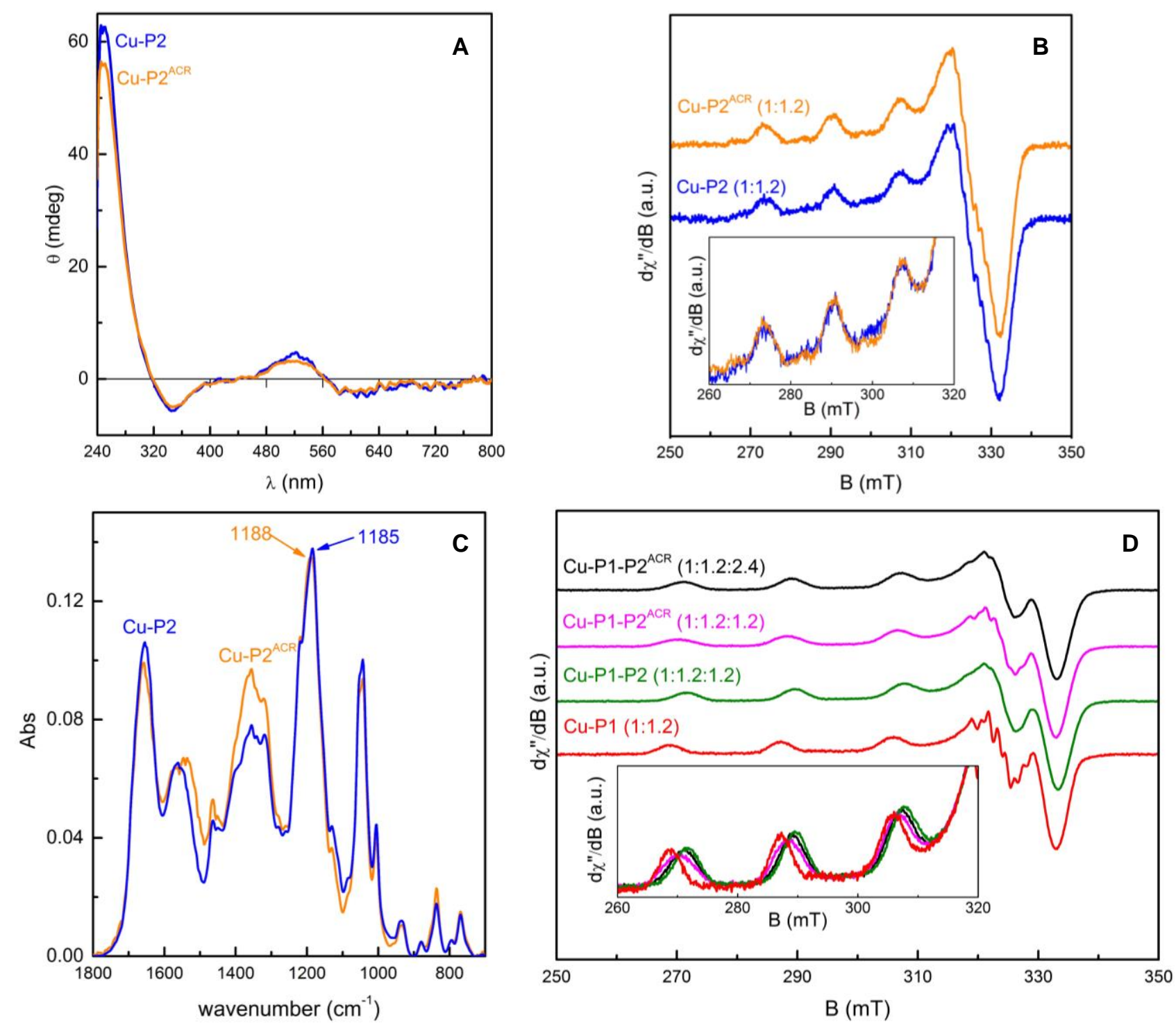

Figure 4. $C D(A)$, normalized EPR (B) and FTIR (C) spectra of Cu-P2 (blue), and Cu-P2 ${ }^{A C R}$ (orange). Conditions: $\left.A\right)\left[\mathrm{Cu}^{2+}\right]=[$ peptides] =

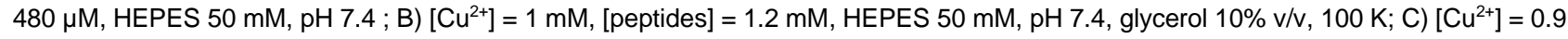
$\mathrm{mM}$, [peptides] = $1 \mathrm{mM}$, HEPES $50 \mathrm{mM}, \mathrm{pH}$ 7.4. D) Normalized EPR spectra of Cu-P1 1:1.2 (red), Cu-P1-P2 1:1.2:1.2 (green), Cu-P1P2ACR 1:1.2:1.2, and Cu-P1-P2 ${ }^{A C R}$ 1:1.2:2.4 (black). Conditions: $\left[\mathrm{Cu}^{2+}\right]=1 \mathrm{mM}, \mathrm{HEPES} 50 \mathrm{mM}$, pH 7.4, glycerol $10 \% \mathrm{v} / \mathrm{v}, 100 \mathrm{~K}$.

His modification does not influence ROS production by $\mathrm{Cu}^{2+}-\alpha \mathrm{Syn}$ model peptides

The redox activity of Cu- $\alpha$ Syn has raised as a possible pathological factor in PD, as it influences ROS production and the oxidation of aSyn itself.[35-38] The Cu-catalysed ROS production in the presence of ascorbate (Figure 5A) can be spectroscopically monitored through the consumption of the substrate, reduced ascorbate (AscH-). Therefore, the effect of His modification on the ability of $\mathrm{Cu}^{2+}$-complexes to catalyze ROS production in the presence of ascorbate was evaluated (Figures 5B and 5C). Cu-P1-P2 and Cu-P1-P2ACR show the same activity (in the experimental error) as $\mathrm{Cu}-\mathrm{P} 1$. The activity is much lower than free $\mathrm{Cu}$ and $\mathrm{Cu}$ $\mathrm{P} 2 / \mathrm{P} 2{ }^{\mathrm{ACR}}$, in line with the higher $\mathrm{Cu}^{2+}$-affinity of $\mathrm{P} 1$ and hence little free $\mathrm{Cu}^{2+}$ present at the beginning. The fact that binding of $\mathrm{P} 2$ and $\mathrm{P} 2^{\mathrm{ACR}}$ has no impact can be due to the following reasons. The affinity of P2/P2ACR to $\mathrm{Cu}-\mathrm{P} 1$ is relatively low, so that at micromolar concentration used in this assay $\left(\left[\mathrm{Cu}^{2+}\right]=1 \mu \mathrm{M}\right)$ species 1 is present rather than species 1 '. Moreover, these considerations are limited to the main $\mathrm{Cu}^{2+}$ state, but the $\mathrm{Cu}^{+}$ is also relevant as it is the dominant state in presence of ascorbate. $\mathrm{Cu}^{+}$binds differently from $\mathrm{Cu}^{2+}$, probably only to the P1 Met1- $\mathrm{X}_{3}-$ Met5 motif and not to His of P2. ${ }^{[39]}$ Moreover, during redox cycling Cu ions are likely 
coordinated differently. ${ }^{[40]}$ In conclusion, ACR-modified His in P2 ${ }^{A C R}$ did not significantly impact the ROS production under the present conditions.

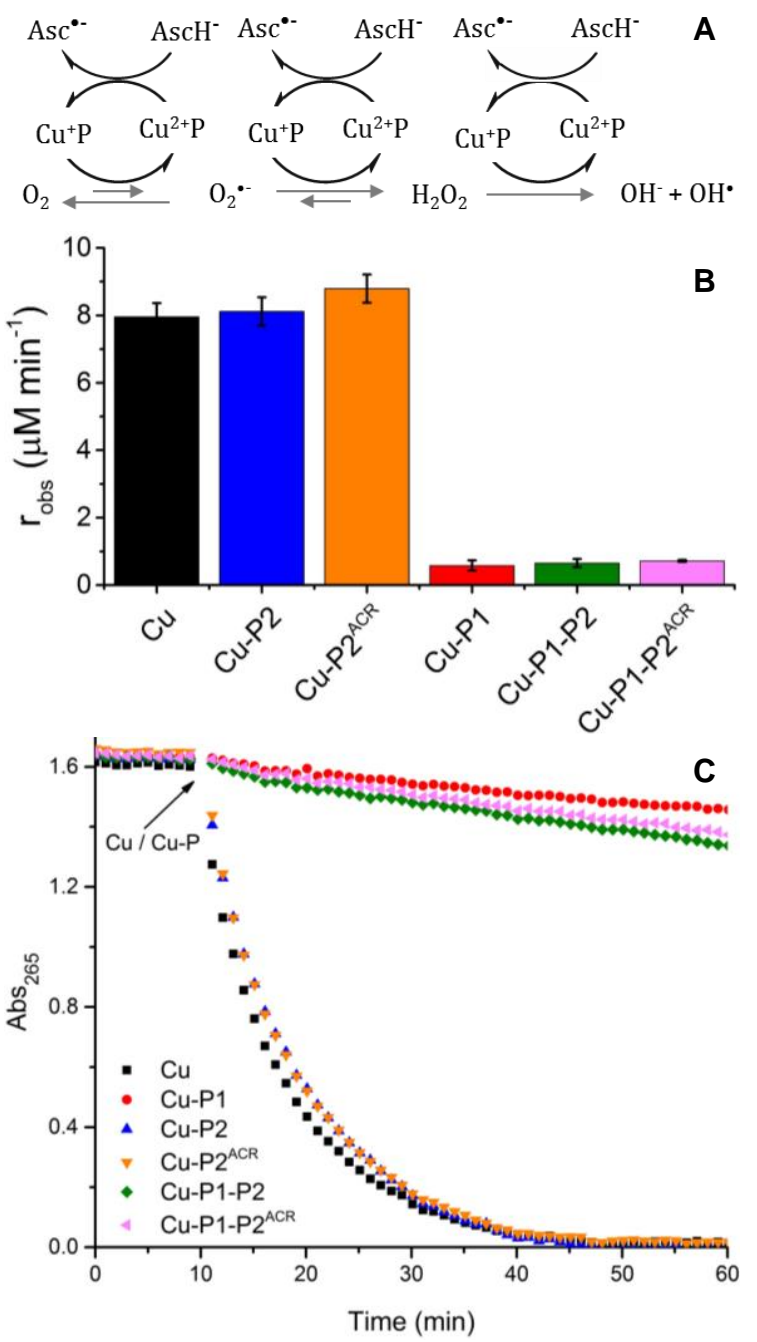

Figure 5. A) Mechanism of Cu-catalysed ROS production in the presence of ascorbate ( $\left.\mathrm{AscH}^{-}\right)$and dioxygen. B) Initial molar rate (B) and kinetics plot (C) of ascorbate oxidation catalysed by "free" $\mathrm{Cu}^{2+}$ (black), Cu-P1 (red), Cu-P2 (blue), Cu-P1-P2 (green), Cu-P2ACR (orange), and Cu-P1-P2ACR (magenta), monitored by ascorbate consumption at $\lambda=265 \mathrm{~nm}$. Conditions: $\left[\mathrm{Cu}^{2+}\right]=1 \mu \mathrm{M}$, [peptides] $=3 \mu \mathrm{M}$, HEPES $50 \mathrm{mM}, \mathrm{pH} 7.4$.

\section{$A C R$ and $\mathrm{Cu}^{2+}$ affect $\alpha$ Syn aggregation}

It is well established that aSyn aggregation is involved in the formation of Lewy bodies, a pathological hallmark in PD. ${ }^{[4,5]}$ To obtain more information about the association/aggregation state of aSyn during the incubation in the presence and absence of ACR and $\mathrm{Cu}^{2+}$, the hydrodynamic diameter $\left(d_{H}\right)$ of the protein at the early stages of aggregation was determined by dynamic light scattering (DLS) measurements. In particular, the derived count rate (DCR) of scattered photons (a function of both the number of the scatterers and their size), the intensity and volume distribution, were monitored over time (Figure 6). The DCR of unmodified aSyn remained constant for $\sim 72 \mathrm{~h}$. Then it increased exponentially, suggesting the formation of aggregates as expected. Instead, when aSyn was incubated with ACR, the formation of large aggregates was inhibited in the measured timescale.

The addition of $\mathrm{Cu}^{2+}$ to aSyn, instead, caused an increase of the DCR, which then did not significantly change over time (Figure 6A). Similarly, the concomitant presence of ACR determined an enhanced DCR, which then remained fairly constant. However, ACR reduced the effect of $\mathrm{Cu}^{2+}$, giving rise to $\mathrm{DCR}$ values in between the initial aSyn/aSyn-ACR ones and those of $\mathrm{Cu}^{2+}-$ aSyn (Figure 6A).

The described trends can be better explained by the analysis of the volume distribution (Figures $6 \mathrm{~B}$ and $6 \mathrm{C}$ ). In the beginning, unmodified and ACR-incubated aSyn showed a $d_{H}=6.3 \pm 0.3 \mathrm{~nm}$, corresponding to the monomeric natively unfolded $\alpha$ Syn, as previously reported in other studies. ${ }^{[41,42]}$ 


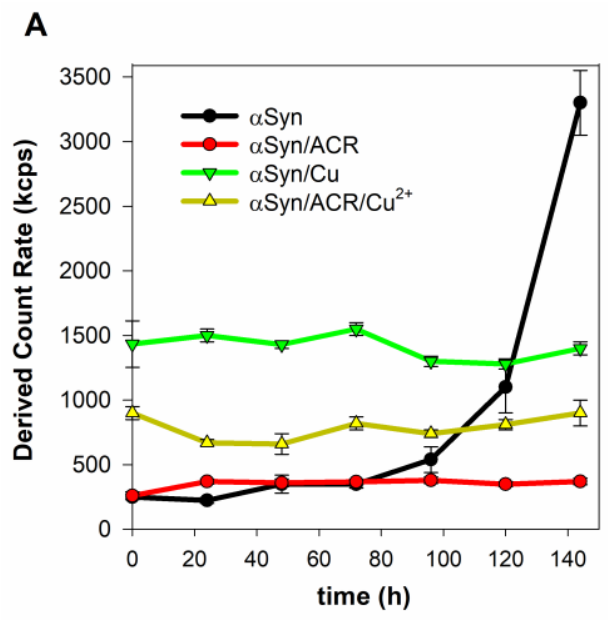

B

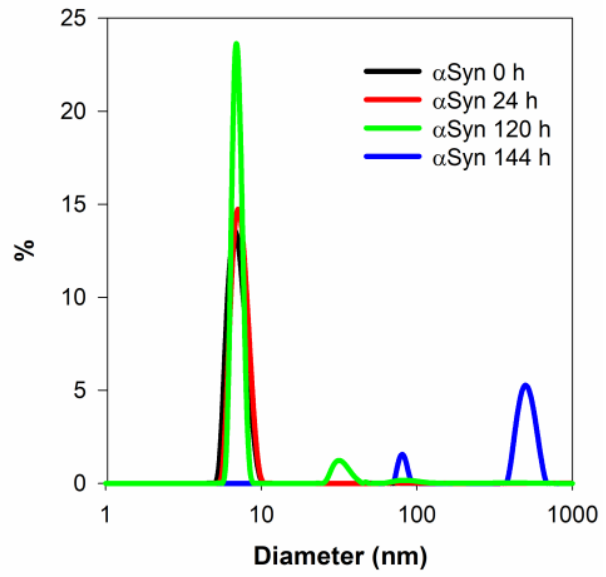

C

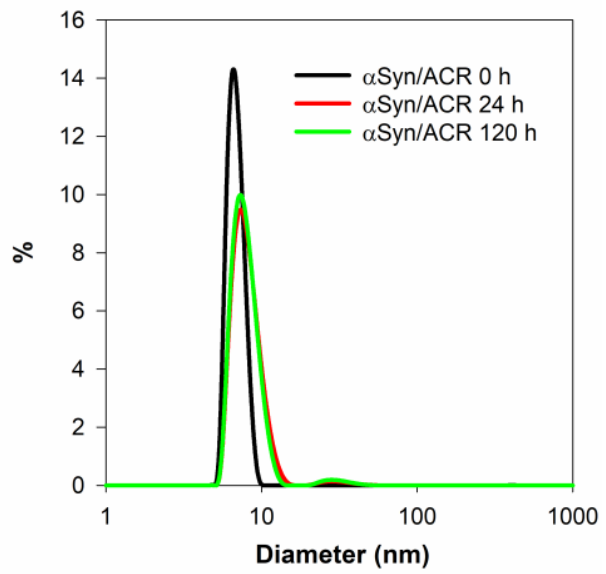

Figure 6. Scattered intensity as a function of time for $\alpha$ Syn alone and the mixtures $\alpha$ Syn:ACR 1:10, $\alpha$ Syn:Cu ${ }^{2+} 1: 2, \alpha S y n: A C R: C u^{2+} 1: 10: 2$. The incubation was performed at $37^{\circ} \mathrm{C}$ for $144 \mathrm{~h}$ in MOPS ( $\mathrm{pH}$ 7.4). The concentration of aSyn for all samples was $100 \mu \mathrm{M}$. The volume distribution of aSyn alone (B) and the mixture aSyn:ACR 1:10 (C) at different times.

After $72 \mathrm{~h}$, in line with the trend given in Figure 6A, untreated aSyn revealed the presence of aggregates at $t=$ $120 \mathrm{~h}$ together with the signal resulting from the aSyn monomer. At $144 \mathrm{~h}$, DLS measurements were not able to reveal the presence of monomers, but populations of aggregates were detected. When aSyn was incubated with ACR, the formation of large aggregates was completely inhibited (Figure 6C). The $d_{H}$ value slightly increased within a period of $24 \mathrm{~h}$, and it can also be noted the presence of a small percentage of aggregates with a mean diameter of $26 \mathrm{~nm}$ that potentially represents small oligomers such as dimers, trimers, and tetramers of aSyn. A similar trend has been previously reported in the presence of ACR but also in the case of nitrated forms of $\alpha$ Syn. ${ }^{[22,41,43]}$ In particular, the formation of aSyn species corresponding to $\alpha$ Syn dimers and trimers in the presence of ACR have been observed by western-blot analysis both in vitro and in vivo 
samples.[21-23] These small oligomers could cause the inhibition of the fibrillation similarly to other dimers of aSyn. ${ }^{44]}$

Instead, the addition of $\mathrm{Cu}^{2+}$ to a aSyn solution instantly caused the formation of a small percentage of aggregates with a mean diameter of $44 \pm 3 \mathrm{~nm}$ (Figure S13). The size and relative population of small oligomers did not change significantly during the incubation. However, the main population was centered to $6.8 \pm 0.2 \mathrm{~nm}$ indicating that the main species was probably the monomer until the end of the incubation. However, the concomitant presence of ACR sharply reduced the formation of these aggregates, as also suggested by the DCR plot.

The ability of ACR to modulate the aSyn oligomerization also has a substantial effect on the formation of amyloid fibrils, which we monitored by the ThT-based assay (Figure S14). The fluorescence intensity had a sigmoid-type trend, thus confirming the behavior of aSyn to show an amyloid-type aggregation. The coincubation with ACR had not any significant effect on the aggregation extent (the maximum fluorescence gain during the aggregation process), but significantly delayed the incipit of the fibril formation, almost doubling the lag phase value $(79.6 \pm 0.6 \mathrm{~h})$ with respect to that showed by aSyn alone $(43.8 \pm 0.7 \mathrm{~h})$. On the contrary, $\mathrm{Cu}^{2+}$ speed up the amyloid-type aggregation of aSyn (Figure S15), as already reported. ${ }^{[42]}$ When $\mathrm{Cu}^{2+}$ and ACR are co-incubated with aSyn, the aggregation process is abolished within the timeframe of the experiment, confirming the trend reported by the DLS measurements.

Overall, ACR inhibited the aggregation process of aSyn both in the presence and in the absence of $\mathrm{Cu}^{2+}$. Only the formation of small oligomers could be observed in the presence of ACR.

\section{Conclusions}

In this work, the combined effects of $\mathrm{Cu}^{2+}$ coordination and ACR-mediated carbonylation towards aSyn were thoroughly investigated through several techniques and approaches. The experimental approach based on LC-MS/MS was useful to assess that i) ACR targets the unique His residue and most of the Lys residues of aSyn in a dose and time-dependent manner, ii) $\mathrm{Cu}^{2+}$ regio-selectively inhibits the ACR modification to the His50 and iii) such an effect is related to the $\mathrm{Cu}^{2+}$ coordination properties of the His residue. The spectroscopic studies of $\mathrm{Cu}^{2+}$ complexes with model peptides encompassing the binding sites of aSyn revealed that the modification by ACR decreases His affinity for $\mathrm{Cu}^{2+}$ in species $1^{1}$. This species may arise from both an intramolecular macro-chelate or $\mathrm{Cu}^{2+-}$-bridged oligomers. ${ }^{[45]}$ In both scenarios, the decreased affinity of species 1 ' in ACR-modified aSyn might impact the metal-induced protein aggregation. Indeed, it could influence the morphology of aSyn aggregates, as His50-dependent macrochelation has been shown to modulate aSyn aggregates polymorphism, ${ }^{[46]}$ and it could interfere with the formation of $\mathrm{Cu}^{2+}$-bridged oligomers. In this study, we show that ACR modification of aSyn inhibits the protein aggregation process, both in the absence and presence of $\mathrm{Cu}^{2+}$ ions. Overall, the data reported here highlight the effects of $\mathrm{Cu}^{2+}$ coordination and ACR modification on aSyn and its aggregation. The potential synergistic effects of these two factors might play a role in the onset and progression of Parkinson's disease and other a-synucleinopathies.

\section{Experimental Section}

\section{Chemicals and stock solutions}

Commercially available reagents were used directly unless otherwise noted. ACR was prepared by hydrolysis of the related diethyl acetal $(10 \mathrm{mM})$ in $0.1 \mathrm{M} \mathrm{HCl}$ for $1 \mathrm{~h}$ at room temperature. Stock solutions of $\mathrm{Cu}^{2+}$ salts were prepared in Milli- $Q$ water. Stock solutions of MOPS (3-(N-morpholino) propane sulfonic acid) and HEPES (4-(2-hydroxyethyl)-1-piperazineethanesulfonic acid) buffers $(500 \mathrm{mM}, \mathrm{pH} 7.4)$ were prepared dissolving free acids in Milli-Q water and adjusting the $\mathrm{pH}$ with $\mathrm{NaOH}$. The stock solution of sodium ascorbate (50 mM) was daily prepared in Milli-Q water.

\section{aSyn expression and purification}

Human aSyn was overexpressed and purified as previously reported, $[47]$ with few modifications. Briefly, the $E$. Colistrain (BL21(DE3) was transformed with pRK172-aSyn plasmid. The cells were grown using Luria-Bertani (LB) medium in the presence of Ampicillin $(0.1 \mathrm{mg} / \mathrm{ml})$. Isopropyl $\beta$-D-1-thiogalactopyranoside (IPTG, $0.5 \mathrm{mM})$ was used to induce the protein expression at $37^{\circ} \mathrm{C}$ for 5 hours. The harvested cells were resuspended in a lysis buffer ( $50 \mathrm{mM}$ Tris, $30 \mathrm{mM} \mathrm{NaCl}, 2 \mathrm{mM}$ EDTA, $0.1 \%$ Triton-X 100, pH 8.6) in the presence of lysozyme $(0.3 \mathrm{mg} / \mathrm{ml})$. After $40 \mathrm{~min}$ at $37^{\circ} \mathrm{C}$, the $\mathrm{pH}$ was adjusted to 3.5 with $\mathrm{HCl}$ before the centrifugation of the cell debris (SL40R centrifuge, Thermo scientific, F15-6X100y rotor, 20,000 g, $1 \mathrm{hr}, 4^{\circ} \mathrm{C}$ ). The aSyn content of the supernatant was purified by using an FPLC instrument (Bio-Rad Biologic Duo flow) throughout desalting and ion-exchange chromatographic steps (Hiprep 26/10 desalting, Hiprep DEAE FF 16/10, BioRad UNO Q1). Finally, size exclusion chromatography (Supradex 200 increase 10/30) was applied to isolate the monomer species of $\alpha$ Syn. The purity and the identity of the protein sample were ensured by SDS-PAGE (Bolt ${ }^{\mathrm{TM}} 10 \%$ Bis-tris plus gel) and LC-MS characterization, respectively. 


\section{aSyn-ACR reaction}

aSyn $(20 \mu \mathrm{M})$ was first incubated with a freshly prepared ACR solution $(200 \mu \mathrm{M})$ in $100 \mathrm{mM}$ MOPS buffer $(\mathrm{pH}$ 7.4 at $37^{\circ} \mathrm{C}$ ). The reaction was stopped after 1.5 , 4 , and 21 hours by incubating with $\mathrm{NaBH}_{4}(5 \mathrm{mM})$ for 10 minutes at room temperature. In a dose-dependent experiment, several amounts of ACR (aSyn:ACR 1:1, 1:10 and 1:50) were tested, and the reaction was stopped after 1.5 hours. The effect of $\mathrm{Cu}^{2+}$ on the aSyn modification by ACR was evaluated adding a standardized $\mathrm{CuSO}_{4} \cdot 5 \mathrm{H}_{2} \mathrm{O}$ solution to obtain $1: 1,1: 2$ or $1: 3$ aSyn: $\mathrm{Cu}^{2+}$ molar ratio before the addition of ACR. In order to structurally characterize aSyn-ACR conjugates, the protein content of the reaction mixture was digested with trypsin at $37^{\circ} \mathrm{C}$ overnight at 1:20 trypsin:aSyn molar ratio. The reaction was stopped by diluting the sample with $5 \%$ acetonitrile and $0.05 \%$ TFA in water, before the nanoLC-HRMS analysis

\section{UPLC-HRMS and data analysis}

All protein samples (enzymatically digested or not) were analyzed using a $Q$ Exactive hybrid quadrupoleOrbitrap mass spectrometer (Thermo Scientific) coupled to an Ultimate 3000 HPLC RSLCnano system (Dionex Thermo Scientific) through an EASY-Spray source (Thermo Scientific). The instrumental parameters were set up as previously reported. ${ }^{[48]}$ The extracted ion chromatogram (XIC) of the most abundant charged species of each protein species or peptide fragment was enlisted for peak detection. MagTran software[49] was used to deconvolve the mass spectra of the aSyn-ACR conjugates, whereas MaxQuant software[50] identified the MS/MS analyzed tryptic digested peptides through their XIC. Data from the MS and MS/MS (HCD) spectra were useful in identifying the peptide fragments and the modified residues.

\section{Peptides synthesis}

MDVFM-NH $2\left(P 1, \alpha S_{1-5}\right)$ and Ac-EGVVH-NH $2\left(P 2, \alpha\right.$ Syn $\left._{46-50}\right)$ peptides were synthesized manually through a standard 9-fluorenylmethoxycarbonyl (Fmoc)/tert-Butyl ( $t \mathrm{Bu})$ solid-phase peptide synthesis. In order to obtain C-terminal-amidated peptides, a Fmoc-Rink amide aminomethyl-polystyrene resin (Fmoc-Rink-Amid AM Resin from Iris Biotech, $0.74 \mathrm{mmol} / \mathrm{g}$ loading, 100-200 mesh) was used as the solid support. HBTU (3[bis(dimethylamino)methyliumyl]-3H-benzotriazol-1-oxide hexafluorophosphate) was used as the coupling agent, DIEA (N,N-diisopropylethylamine) as the base and DMF (N,N-dimethyl-formamide) as the solvent. Protected amino acids used were Fmoc-Met-OH, Fmoc-Asp(tBu)-OH, Fmoc-Val-OH, Fmoc-Phe-OH, FmocGlu(tBu)-OH, Fmoc-Gly-OH, Fmoc-His(Trt)-OH). The coupling reactions were performed in a syringe with filter frit by using a 4-fold excess of protected amino acid, a 3.9-fold excess of HBTU, and an 8-fold excess of DIEA for 1 hour under mixing. After coupling, the presence of unreacted $\mathrm{N}$-terminal free amine was checked with TNBS (2,4,6-trinitrobenzenesulfonic acid) reagent, and the coupling was repeated in case of a positive test. Capping of the unreacted free amine group was carried out using $5 \%$ acetic anhydride and $10 \%$ DIEA in DMF for 5 min. N-terminal Fmoc deprotection was carried out using $20 \%$ piperidine in DMF. P2 N-terminal acetylation was carried out with 5\% acetic anhydride and 10\% DIEA in DMF for 15 minutes. Peptides were cleaved and side-chain deprotected at the same time by treatment with 95\% TFA (trifluoroacetic acid), $2.5 \%$ $\mathrm{H}_{2} \mathrm{O}$ and $2.5 \%$ TIS (triisopropylsilane) for $90 \mathrm{~min}$. The crude mixture was directly concentrated under vacuum or precipitated with cold ether. Crudes were purified by RP-HPLC on a C18 column (XBridge Peptide BEH C18 OBD Prep Column from Waters, $19 \mathrm{~mm} \times 150 \mathrm{~mm}$, pore size $130 \AA$ A, particle size $5 \mu \mathrm{m}$ ) using a LaPrep Sigma (VWR International) instrument with UV-vis detection at $214 \mathrm{~nm}$. The purity and identity of the peptides were assessed by analytical HPLC and ESI-MS. Stock solutions were prepared in DMSO or milli-Q water for $\mathrm{P} 1$ and P2 respectively. Carbonylation of P2 was achieved by overnight incubation of the peptide $(500 \mu \mathrm{M})$ with ACR $(10 \mathrm{mM})$ in HEPES buffer $(\mathrm{pH} 7.4)$ at $37^{\circ} \mathrm{C}$ under mixing. The carbonylated peptide (P2 $\left.{ }^{\mathrm{ACR}}\right)$ was purified by RP-HPLC.

\section{NMR spectroscopy}

${ }^{1} \mathrm{H}$ NMR spectra were recorded in $\mathrm{D}_{2} \mathrm{O}$ at $25^{\circ} \mathrm{C}$ with a Varian Unity Plus 500 spectrometer at $499.9 \mathrm{MHz}$ using standard pulse programs from the Varian library. Two-dimensional (2D) experiments were acquired using $1 \mathrm{~K}$ data points and 256 increments. Spectra were referred to the solvent signal.

\section{Spectroscopy}

CD spectra of $\mathrm{Cu}^{2+}$ complexes $\left(\left[\mathrm{Cu}^{2+}\right]=\right.$ [peptides $\left.]=480 \mu \mathrm{M}\right)$ in HEPES buffer $(50 \mathrm{mM}, \mathrm{pH} 7.4)$ were recorded in a $1 \mathrm{~cm}$ path cuvette with a Jasco J-810 spectropolarimeter in the $230-800 \mathrm{~nm}$ range using a scanning speed of $50 \mathrm{~nm} / \mathrm{min}$ and 3 accumulations. CD spectra were smoothed using the Savitzy-Golay method, and the blank was subtracted after the sample measurement.

\section{EPR spectroscopy}

EPR spectra were recorded on a continuous-wave X-band EMX-plus spectrometer (ca. $9.4 \mathrm{GHz}$, Bruker Biospin $\mathrm{GmbH}$, Germany) equipped with a high sensitivity resonator (4119HS-W1, Bruker Biospin GmbH). The $g$ factor calibration was achieved in the experimental conditions by using Bruker standard (strong pitch) with a known isotropic $g$ factor of 2.0028 . All samples were supplemented by $10 \% \mathrm{v} / \mathrm{v}$ glycerol to ensure homogenous protein distributions and avoid water crystallization-induced phase separation. Samples were 
introduced to $4 \mathrm{~mm}$ outer diameter quartz tubes (Wilmad-Labglass) and freeze-quenched into liquid nitrogen before their introduction into the pre-cooled cavity $(100 \mathrm{~K}$, achieved by continuous flow liquid nitrogen cryostat). The main experimental parameter values were: microwave power ca. $0.1 \mathrm{~mW}$; modulation amplitude $5 \mathrm{G}$; conversion time and time constant were setup at ca. 200 and $80 \mathrm{~ms}$, respectively; $1500 \mathrm{G}$ were swept in 5 min, and several spectra were accumulated to ensure a good signal-to-noise ratio (S/N). All experimental EPR spectra were analyzed through computer simulation using lab-made scripts based on the Easyspin toolbox under Matlab (Mathworks) environment. ${ }^{[1]}$

\section{FTIR spectroscopy}

Peptide samples for FTIR were subjected to several cycles of TFA-/Cl- counter-ion exchange via dissolution in $\mathrm{HCl}$ and lyophilization. The FTIR spectra of P2/P2 ${ }^{A C R}(1 \mathrm{mM})$ before and after $\mathrm{Cu}^{2+}(0.9 \mathrm{mM})$ binding in HEPES (50 mM, pH 7.4) were recorded on a Vertex 70 spectrometer (Bruker Optics, Karlsruhe) equipped with a diamond-ATR unit. $2.5 \mu \mathrm{L}$ of samples were deposited on the ATR crystal and left to dry for a few minutes. 5 Spectra of 64 scans each recorded at a scan rate of $20 \mathrm{kHz}$ with a spectral resolution of $4 \mathrm{~cm}^{-1}$ were averaged for each sample.

\section{Kinetics of ascorbate oxidation}

Ascorbate oxidation $\left(\left[\mathrm{AscH}^{-}\right]=100 \mu \mathrm{M}\right)$ was monitored by UV-Vis absorption at $\lambda=265 \mathrm{~nm}$ in HEPES buffer $(50 \mathrm{mM}, \mathrm{pH}$ 7.4) on a Clario Star plate reader inside a 96-wells plate. After monitoring ascorbate oxidation for $10 \mathrm{~min}$, free $\mathrm{Cu}^{2+}$ or $\mathrm{Cu}^{2+}$-peptides solution was added $\left(\left[\mathrm{Cu}^{2+}\right]=1 \mu \mathrm{M}\right.$, [peptide] $\left.=3 \mu \mathrm{M}\right)$. Kinetic measurements of ascorbate oxidation were performed three times in different days with different fresh ascorbate solutions. The molar ascorbate oxidation rate $\left(\mu \mathrm{M} \min ^{-1}\right)$ was obtained by dividing the initial slop of $A b s_{265}(t)$ by the extinction coefficient of $\mathrm{AscH}^{-}\left(\varepsilon 265=14500 \mathrm{M}^{-1} \mathrm{~cm}^{-1}\right)$.

\section{DLS measurements}

Samples were analyzed on a Zetasizer Nano ZS (Malvern Instruments Ltd., UK) equipped with a $\lambda=633 \mathrm{~nm}$ $\mathrm{He}-\mathrm{Ne}$ laser and a Peltier temperature controller set at $37^{\circ} \mathrm{C}$ temperature. The protein samples were prepared at $100 \mu \mathrm{M}$ (aSyn monomer equivalents) and buffered in MOPS (pH 7.4). The effect of ACR and/or $\mathrm{Cu}^{2+}$ on the aggregation of aSyn was evaluated adding a freshly prepared ACR and/or a standardized $\mathrm{CuSO}_{4} \cdot 5 \mathrm{H}_{2} \mathrm{O}$ solution to obtain $\alpha$ Syn:ACR 1:10 and/or $\alpha$ Syn:Cu${ }^{2+}$ 1:2 molar ratios. Disposable, solvent resistant microcuvettes were used for size measurements, which were conducted at a scattering angle of $173^{\circ}$. Each DLS measurement was run by using automated, optimal measurement times and laser attenuation settings. All samples were measured 5-10 times using 15-40 accumulated scans to give averaged $d_{H}$ values.

\section{Aggregation assay}

The aggregation assays of aSyn were carried out by using a turn-on dye (ThT) sensitive to the amyloid-type fibrils. ThT $(40 \mu \mathrm{M})$, aSyn $(70 \mu \mathrm{M})$ and ACR ( $\alpha$ Syn:ACR 1:10) or $\mathrm{Cu}^{2+}\left(\alpha \operatorname{Syn}: \mathrm{Cu}^{2+} 1: 2\right)$ were incubated in MOPS buffer ( $2 \mathrm{mM} \mathrm{pH} \mathrm{7.4)} \mathrm{containing} \mathrm{NaCl} \mathrm{(100} \mathrm{mM)} \mathrm{within} \mathrm{a} \mathrm{96-well} \mathrm{plate} \mathrm{(Nalge-Nunc,} \mathrm{Rochester,} \mathrm{NY)} \mathrm{for} 5$ days at $37^{\circ} \mathrm{C}$ in the Varioskan plate reader (Thermo Scientific) under continuous shaking (600 rpm). The fluorimetric measurements were carried out by monitoring the ThT emission at $482 \mathrm{~nm}$, exciting at $440 \mathrm{~nm}$. All the amyloidtype kinetic measurements were carried out in three different experiments $(n=3)$, and the experimental data were fitted to Equation (1), in which the fitted parameters are the starting $\left(F_{0}\right)$ and final $\left(F_{\text {max }}\right)$ fluorescence emissions of the amyloid aggregation process, the elongation rate constant $(1 / \mathrm{k})$ and the time at which the amplitude of ThT emission is $50 \%$ of the $F_{\max }-F_{0}$ value $\left(t_{1 / 2}\right)$. The last two parameters contribute to calculate (Equation 2) the lag time ( $\left.t_{\text {lag }}\right)$, defined as the intercept between the time axis and the tangent of the curve with slope $\mathrm{k}$ from the midpoint of the fitted sigmoidal curve.

$$
\begin{aligned}
& F(t)=F_{0}+\frac{F_{\max }-F_{0}}{1+e^{-\frac{t-t_{1 / 2}}{k}}} \\
& t_{\text {lag }}=t_{1 / 2}-2 k
\end{aligned}
$$

The kinetic parameters were expressed as means \pm SEM of three different experiments $(n=3)$.

\section{Acknowledgements}

The authors thank Dr. Jennifer C. Lee (NIH-Laboratory of molecular biophysics, Bethesda) and Dr. Michel Goedert (MRC Laboratory of Molecular Biology, Cambridge) for kindly providing the aSyn expression vector, Dr. Francesca Guarino and Dr. Andrea Magrì (Department of Biomedical and Biotechnological Sciences, University of Catania) for the great help about the E.Coli transformation, Dr. Laurent Raibaut and Dr. Vincent Lebrun (UMR 7177, Strasbourg) for fundamental help with the peptide synthesis. The authors also 
acknowledge financial support from the INCIPIT-COFUND project co-funded by HORIZON 2020/Marie Sklodowska Curie Actions, from the French National Research Agency (ANR) through the Programme d'Investissement d'Avenir under contract 17-EURE-0016, Università degli Studi di Catania (Piano della Ricerca di Ateneo) and the Italian Ministero dell'Università e della Ricerca.

\section{References}

[1] E. Gaggelli, H. Kozlowski, D. Valensin, G. Valensin, Chem. Rev. 2006, 106, 1995-2044.

[2] K. Jomova, D. Vondrakova, M. Lawson, M. Valko, Mol. Cell. Biochem. 2010, 345, 91-104.

[3] C. Haass, H. Steiner, Nat. Neurosci. 2001, 4, 859-860.

[4] Y. C.Wong, D. Krainc, Nat. Med. 2017, 23, 1.

[5] V. Oliveri, Eur. J. Med. Chem. 2019, 167, 10-36.

[6] H. S. Pall, D. R. Blake, J. M. Gutteridge, A. C. Williams, J. Lunec, M. Hall, A. Taylor, Lancet 1987, 330, $238-241$.

[7] X. Wang, D. Moualla, J. A. Wright, D. R. Brown, J. Neurochem. 2010, 113, 704-714.

[8] C. Wang, L. Liu, L. Zhang, Y. Peng, F. Zhou, Biochemistry 2010, 49, 8134-8142.

[9] A. Binolfi, L. Quintanar, C. W. Bertoncini, C. Griesinger, C. O. Fernández, Coord. Chem. Rev. 2012, 256, $2188-2201$.

[10] Binolfi, E. E. Rodriguez, D. Valensin, N. D’Amelio, E. Ippoliti, G. Obal, R. Duran, A. Magistrato, O. Pritsch, M. Zweckstetter, G. Valensin, P. Carloni, L. Quintanar, C. Griesinger, C. O. Fernández, Inorg. Chem. 2010, 49, 10668-10679.

[11] T. Kowalik-Jankowska, A. Rajewska, K. Wisniewska, Z. Grzonkab, J. Jezierska, J. Inorg. Biochem. 2005, 99, 2282-2291

[12] T. Kowalik-Jankowska, A. Rajewska, E. Jankowska, Z. Grzonkab, Dalton Trans. 2006, 5068-5076.

[13] D.Valensin, F. Camponeschi, M. Luczkowski, M. C. Baratto, M. Remelli, G. Valensin, H. Kozlowski, Metallomics 2011, 3, $292-302$.

[14] R. De Ricco, D. Valensin, S. Dell'Acqua, L. Casella, P. Dorlet, P. Faller, C. Hureau, Inorg. Chem. 2015, 54, 4744-4751.

[15] D. L. Abeyawardhane, D. R. Heitger, R. D. Fernández, A. K. Forney, H. R. Lucas, ACS Chem. Neurosci. 2019, 10, $1402-1410$.

[16] T. T. Reed, Free Radic. Biol. Med. 2011, 51, 1302-1319.

[17] L. Shen, C. Chen, A. Yang, Y. Chen, Q. Liu, J. Ni, J. Proteomics 2015, 123, 101-113.

[18] P. R. Angelova, M. H. Horrocks, D. Klenerman, S. Gandhi, A. Y. Abramov, M. S. Shchepinov, J. Neurochem. 2015, 133, 582-589.

[19] E. Dalfó, I. Ferrer, Neurobiol. Aging 2008, 29, 408-417.

[20] M. Shamoto-Nagai, W. Maruyama, Y. Hashizume, M. Yoshida, T. Osawa, P. Riederer, M. J. Naoi, Neural Transm. 2007, 114, 15591567.

[21] Y. T. Wang, H. C. Lin, W. Z. Zhao, H. J. Huang, Y. L. Lo, H. T. Wang, A. M. Y. Lin, Sci. Rep. 2017, 7, 45741.

[22] A. Ambaw, L. Zheng, M. A. Tambe, K. E. Strathearn, G. Acosta, S. A. Hubers, F. Liu, S. A. Herr, J. Tang, A. Truong, El. Walls, A. Pond, J. C. Rochet, R. Shi, Mol. Cell. Neurosci. 2018, 88, 70-82.

[23] G. Acosta, N. Race, S. Herr, J. Fernandez, J. Tang, E. Rogers, R. Shi, Mol. Cell Neurosci. 2019, 98, 140-154.

[24] R. J. Castellani, G. Perry, S. L. Siedlak, A. Nunomura, S. Shimohama, J. Zhang, T. Montine, L. M. Sayre, M. A. Smith, Neurosci. Lett. 2002, 319, 25-28.

[25] S. Zhang, E. Eitan, T. Y. Wu, M. P. Mattson, Neurobiol. Aging 2018, 61, 52-65.

[26] A. Trostchansky, S. Lind, R. Hodara, T. Oe, I. A. Blair, H. Ischiropoulos, H. Rubbo, J. M. Souza, Biochem. J. 2006, 393, $343-349$.

[27] W. Xiang, S. Menges, J. C. M. Schlachetzki, H. Meixner, A. C. Hoffmann, U. Schlötzerr-Schrehardt, C. M. Becker, J. Winkler, J. Klucken, Mol. Neurodegener. 2015, 10, 1-16.

[28] J. Cai, A. Bhatnagar, W. M. Pierce Jr., Chem. Res. Toxicol. 2009, 22, 708-716.

[29] G.I. Grasso, F. Bellia, G. Arena, C. Satriano, G. Vecchio, E. Rizzarelli, Eur. J. Med. Chem. 2017, 135, 447-457.

[30] K. Uchida, Amino Acids 2003, 25, 249-257.

[31] K. Uchida, E. R. Stadtman, Proc. Natl. Acad. Sci. U. S. A. 1992, 89, 4544-4548.

[32] K. Hasegawa, T. Ono, T. Noguchi, J. Phys. Chem. A, 2002, 106, 3377-3390.

[33] P. Chakrabarti, Protein Eng. Des. Sel., 1990, 4, 57-63.

[34] S. Karlin, Z. Zhu, K. D. Karlin, Proc. Natl. Acad. Sci., 1997, 94, 14225-14230.

[35] S. Dell'Acqua, V. Pirota, C. Anzani, M. M. Rocco, S. Nicolis, D. Valensin, E. Monzani, L. Casella, Metallomics 2015, 7, $1091-1102$.

[36] T. Kowalik-Jankowska, A. Rajewska, E. Jankowska, Z. Grzonka, Dalton Trans. 2008, 832-838.

[37] M. C. Miotto, E. E. Rodriguez, A. A. Valiente-Gabioud, V. Torres-Monserrat, A. Binolfi, L. Quintanar, M. Zweckstetter, C. Griesinger, C. O. Fernández, Inorg. Chem. 2014, 53, 4350-4358.

[38] M. K. Tiwari, F. Leinisch, C. Sahin, I. M. Møller, D. E. Otzen, M. J. Davies, M. J. Bjerrum, Free Radic. Biol. Med. 2018, 121, 38-50.

[39] R. De Ricco, D. Valensin, S. Dell'Acqua, LI Casella, E. Gaggelli, G. Valensin, L. Bubacco, S. Mangani, Inorg. Chem. 2015, 54, 265-272.

[40] E. Atrián-Blasco, P. Gonzales, A. Santoro, B. Alies, P. Faller, C. Hureau, Coord. Chem. Rev. 2018, 375, 38-55.

[41] G. Yamin, V. N. Uversky, A. L. Fink, FEBS Lett. 2003, 542, 147-152.

[42] V. Oliveri, C. Sgarlata, G. Vecchio, Chem.-Asian J. 2016, 11, 2436-2442.

[43] V. N. Uversky, G. Yamin, L. A. Munishkina, M. A. Karymov, I. S. Millett, S. Doniach, Y.L. Lyubchenko, A. L. Fink, Mol. Brain Res. 2005, 134, 84-102.

[44] Y. A. Kyriukha, K. Afitska, A. S. Kurochka, S. Sachan, M. Galkin, D. A. Yushchenko, V. V. Shvadchak, J. Med. Chem. 2019, DOI: 10.1021/acs.jmedchem.9b01400.

[45] S. C. Drew, Chem. Eur. J. 2015, 21, 7111-7118.

[46] T. S. Choi, J. Lee, J.Y. Han, B. C. Jung, P. Wongkongkathep, J. A. Loo, M. J. Lee, H. I. Kim, Angew. Chem.-Int. Ed. 2018, 57, 30993103.

[47] M. Pfefferkorn, J. C. Lee, Methods Mol. Biol. 2012, 895, 197-209.

[48] F. Bellia, V. Lanza, S. García-Viñuales, I.M.M. Ahmed, A. Pietropaolo, C. lacobucci, G. Malgieri, G. D'Abrosca, R. Fattorusso, V.G. Nicoletti, D. Sbardella, G.R. Tundo, M. Coletta, L. Pirone, E. Pedone, D. Calcagno, G. Grasso, D. Milardi, Chem. Sci. 2019, 10, $2732-2742$.

[49] Z. Zhang, A. G. Marshall, J. Am. Soc. Mass Spectrom. 1998, 9, 225-233.

[50] J. Cox, M. Mann, Nat. Biotechnol. 2008, 26, 1367-1372.

[51] S. Stoll, A. Schweiger, J. Magn. Res. 2006, 178, 42-55. 